\section{INOVAÇÕES TECNOLÓGICAS: UM ESTUDO DO PROCESSO DE PRODUÇÃO DE CARTEIRA DE IDENTIDADE DE PARANAIBA-MS}

\section{TECHNOLOGICAL INNOVATIONS: A STUDY OF THE PROCESS OF PRODUCTION OF IDENTITY CARD OF PARANAÍBA-MS}

\author{
Dieici ferreira Silva ${ }^{1}$ \\ Carlos Rodrigues da Silva ${ }^{2}$
}

\begin{abstract}
Resumo
A pesquisa tem como objetivo demonstrar as contribuições das inovações tecnológicas na produção de carteira de identidade. $\mathrm{O}$ método de pesquisa foi qualitativo-descritivo. $\mathrm{O}$ ambiente pesquisado foi o processo de inovação implantado na Unidade Regional de Perícias e Identificação (URPI) - um órgão público do Estado de Mato Grosso do Sul. Foi entrevistado o responsável pelo setor pesquisado. Os resultados indicaram aspectos positivos da adoção da inovação, tanto no procedimento operacional (satisfação do trabalhador) como dos clientes; no entanto constatou que há carência de pessoal para executar os serviços prestado pelo Instituto de Identificação.
\end{abstract}

Palavras-chave: Adoção de inovação. Gestão pública. Processo de inovação

\begin{abstract}
The research aims to demonstrate the contributions of technological innovations in the production of identity card. The method of research was qualitative-descriptive. The researched environment was the innovation process implemented in the Regional Unit of Expertise and Identification (URPI) - a public agency of the State of Mato Grosso do Sul. The person in charge of the sector surveyed was interviewed. The results indicated positive aspects of the adoption of innovation, both in the operational procedure (employee satisfaction) and in the clients; nevertheless noted that there is a shortage of personnel to perform the services provided by the Identification Institute.
\end{abstract}

Key-words: Innovation adoption. Public administration. Innovation Process

\footnotetext{
${ }^{1}$ Aluno de Graduação em Administração pela Universidade Estadual do Oeste do Paraná. E-mail: rafaelkawacki@hotmail.com

2 Doutora em Administração pela Pontifícia Universidade Católica do Paraná, Brasil (2010). Coordenadora do Curso de Administração da Universidade Estadual do Oeste do Paraná, Brasil. E-mail: silvanaanita.walter@gmail.com

${ }^{3}$ Pós-Doutor EAESP/FGV São Paulo, Brasil. E-mail: mario.soares@ unioeste.br
}

Artigo recebido em: 28 de fevereiro de 2018. Artigo aceito em 06 de dezembro de 2018. 


\section{Introdução}

De acordo com Manual de Oslo (2005), inovação é a realização ou o melhoramento de um produto, bem ou serviço moderno, e também pode ser um processo, nova tática organizacional das práticas dos afazeres, na empresa, no ambiente de trabalho e nas ligações externas. A presente pesquisa destaca as inovações tecnológicas implantadas no Instituto de Identificação localizado na Unidade Regional de Perícias e identificação de Paranaíba/MS, e suas contribuições na produção de carteira de identidade.

Como o Manual de Oslo (2005) destaca a comunicação de informação é vital para o desenvolvimento econômico, afirma que a inovação evoluiu com o passar dos anos, tornando-se necessário que indicadores de mudanças, oferecerem aos formuladores de políticas, mecanismo apropriado de análise, que forneça conhecimento central em inovação, pois a globalização trouxe um crescimento de produto e produtividade para dentro das empresas, a economia mundial evoluiu, ocorrendo o mesmo com o processo de inovação, acarretando crises às empresas, no que diz respeito ao acesso à informação e a novos mercados, trazendo uma competição internacional, tendo que enfrentar novas formas de encarar as cadeias de fornecimento global.

As mudanças tecnológicas estão interligadas ao sistema inovador, Schumpeter (1912) traz o método da inovação em três fases: a invenção ocupa a primeira etapa ela pode ser ou não viável financeiramente, por ser uma nova ideia, a inovação é gerada após a invenção o propósito é que seja financeiramente viável, e após comercializar e divulgar um novo produto ou processo.

A partir deste contexto, a busca do conhecimento de como a inovação ocorre no setor público, direcionou para a seguinte pergunta: Quais os tipos de inovações tecnológicas que o Instituto de Identificação de Paranaíba/MS utiliza no processo de produção de carteira de identidade e quais as contribuições decorrentes dessa inovação?

Com vista responder a presente pergunta o objetivo da pesquisa é identificar as inovações e suas contribuições utilizadas na produção de carteira de identidade.

Justifica-se a pesquisa por tratar de um tema pouco pesquisada no ambiente público, que é o foco desta pesquisa. Assim, é uma contribuição para a academia, por apresentar uma contribuição teórica em um ambiente pouco pesquisado. Outrossim, serve àqueles que queiram utilizar a tecnologia, objeto da pesquisa empírica. Evidencia 


\section{SILVA; SILVA}

a importância das inovações tecnológicas no processo de produção, analisando os impactos que elas proporcionam aos envolvidos no processo. As novas tecnologias contribuem bastante para o bom desenvolvimento no processo de produção de carteiras de identidade, agilidade e praticidade no atendimento da população. Está pesquisa é viável, pois não houve barreiras para a coleta de informações e dados através da entrevista.

$\mathrm{O}$ artigo foi organizado em 5 diferentes tópicos: no primeiro apresentou-se o problema de pesquisa, objetivo e a justificativa; no segundo fundamentou-se o suporte teórico; no terceiro evidenciou os métodos e procedimentos da pesquisa; no quarto foi apresentada e analisada a pesquisa de campo; e, no quinto, buscou-se concluir a presente pesquisa.

\section{Inovação}

Diversas mudanças podem ocorrer dentro de uma empresa, com a aplicação de métodos distintos na produção, para posteriormente ter resultados que aumenta a sua produtividade, um dos mecanismos útil é a adoção da inovação, o manual descreve quatro tipos de inovações que formam uma grande soma de mudanças nas atividades das empresas que são: inovações de produto, inovações de processo, inovações organizacionais e inovações de marketing (MANUAL DE OSLO, 2005).

Vale destacar a contribuição ao significado assumido pela inovação, através da economia, a inovação associada a novos produtos, compete aqui classificar os tipos de inovação que uma empresa tem capacidade de gerar e compreender as inovações mercadológicas, organizacionais e tecnológicas. Tomando por base a terceira edição do Manual de Oslo, estudo publicado pela Organização para Cooperação e Desenvolvimento.

A inovação mercadológica, conhecida por marketing, está ligada a novas praticas e métodos de aplicação do marketing, com mudanças expressivas na aparência do produto, embalagem, a posição do produto, sua promoção, e fixação de preços; as inovações organizacionais fazem referência a prática de novos procedimentos de organização e gestão de negócio na empresa, do seu local de trabalho ou em suas relações com atores externos, como fornecedores ou distribuidores. $\mathrm{Na}$ inovação de processo, é destacada a robotização na linha de fabricação de automóveis. Além disso, a 


\section{SILVA; SILVA}

evolução histórica da indústria automobilística é forte em modelos de inovações de processo, com ênfase para as linhas de produção fordismo expandindo no início da década do século XX (MANUAL DE OSLO, 2006).

A proximidade entre as inovações de processo e as inovações organizacionais, sendo ambas voltadas à diminuição dos custos pela introdução de novos conceitos produção eficiente, distribuição e organização interna. Como ressaltado no Manual de Oslo, a caracterização entre elas é o tipo de atividade: destacando que as inovações de processos se tratam de implementações de novos equipamentos, softwares, técnicas ou procedimentos enquanto as inovações organizacionais lidam, primordialmente, com pessoas e a organização do trabalho (MANUAL DE OSLO, 2006).

Schumpeter (1943) trata a inovação com novas combinações de materiais e forças, dando contribuição fundamental no desenvolvimento econômico, abrindo novos mercados. Em um de seus trabalhos, o autor cita cinco novas combinações ou inovações, a saber:

- Introdução de um novo bem, ou seja, um bem com que os consumidores ainda não estão familiarizados, ou de uma nova qualidade de um bem;

- Introdução de um novo método de produção, ou seja, um método que ainda não tenha sido testado pela experiência no ramo próprio da indústria de transformação, que de algum modo, precisa estar baseada numa descoberta cientificamente nova, e pode constituir uma nova maneira de manejar comercialmente uma mercadoria;

- Abertura de um novo mercado, ou seja, de um mercado em que o ramo particular da indústria de transformação do país em questão não tenha ainda entrado, que esse mercado tenha existido antes ou não;

- Conquista de uma nova fonte de oferta de matérias-primas ou de bens semimanufaturados, mais uma vez independentemente do fato de que essa fonte já existia ou teve que ser criada;

- Estabelecimento de uma nova organização de qualquer indústria, como a criação de uma posição de monopólio ou a fragmentação de uma posição de monopólio.

\subsection{Tipos de inovação}

Revista Eletrônica Gestão e Serviços v.9, n. 2, pp. 2413-2431, julho/dezembro 2018. ISSN Online: 2177-7284 e-mail: regs@ metodista.br 


\subsubsection{Inovação de processo}

A administração de operações refere se aos processos os quais produzem bens e serviços, o processo é basicamente um conjunto de atividades fundamentais utilizadas pelas empresas para realizar tarefas e alcançar suas metas, transformando e agregando valor a partir dos insumos, que são: recursos humanos, capital, materiais e serviços adquiridos, imóveis e energia; o tipo de processos pode variar de acordo com cada segmento das organizações, pode se tratar de uma fábrica em que o processo primário se trata de uma transformação de matérias-primas em produtos; porém existem processos não relacionados ás indústrias diretamente, empresas que proporciona serviços através de suas instalações (RITZMAN et al., 2004).

Segundo o Manual de Oslo (2005), inovação de processo é algo novo trazendo melhorias na produção, podem ser mudanças com resultados positivos em equipamentos, técnicas, softwares etc. Ela diminui custos de produção e aumenta a qualidade. É a inovação ou a melhoria de algo já existente. Inclui mudanças essenciais nos equipamentos e nos softwares aplicados em corporações preparadas para serviço ou nos mecanismos e nas práticas utilizadas para uma atividade de posição.

Inovar um processo inclui mudanças que irão modificar totalmente ou parcialmente as atividades para formar determinado produto, quando se introduz a tecnologia, torna-se grande aliada para aperfeiçoar os produtos, reduzir custos que na fase anterior eram frequentes e torná-los mais competitivos quanto à sua entrega aos consumidores (TIGRE, 2006).

Diante da gama diversificada de empresas, algumas não conseguem estabilidade no mercado com determinadas inovações em seus processos ou mudanças organizacionais, logo, será preciso se apagar do mercado e se levantar com inovações totalmente diferentes das quais apresentou anteriormente, pois a compra de uma máquina não consegue dar o privilégio à empresa como inovadora porque além de ser propensa à obsolescência deverá atender outros setores com carência de tecnologia, por fim, a alternativa é alterar partes do processo produtivo para atender as cobranças de novos produtos (SCHUMPETER, 1961).

A tecnologia em sua essência procura ser contemplada após estudos criteriosos que são elaborados com base nas informações concedidas pelas empresas, possuem o foco voltado diretamente para a produção porque é nesse objetivo que se permite a 


\section{SILVA; SILVA}

criação de novas ferramentas, precisam superar as dificuldades produtivas e resultar em bons produtos (LIMA; MENDES, 2003).

Segundo Tigre (2006), há outras empresas com estratégias diferentes de como introduzem a tecnologia em suas operações diárias, conhecida como empresa imitativa, pode ser alguma empresa terceirizada, pequena ou não, da empresa de grande porte, o que acontece é a introdução da mesma mudança que a imitativa considera aplicável da qual se espelha. A outra é a dependente, pelo próprio nome, nunca toma a decisão de inovação por depender fortemente da inovação da grande empresa ou por ter a sede como matricial, então estrutura, processos, ideias, máquinas, softwares somente são introduzidos como a permissão ou criação de algo novo da matriz ou da grande empresa.

Processo é uma tarefa, ou uma união de tarefas, que contém utilidade e validade a um cliente essencial, podendo através de recursos, trazerem resultados positivos. Movimentos de máquinas e pessoas é uma forma de processo empresarial, e quando o processo é em empresas de produção, torna-se mais fácil de analisar os períodos que apresentam ou não problemas e quando obtém ou não resultados. Esses fatores de produção colaboram para a empresa inovar tanto na esfera organizacional como nos processos (GOLÇALVES, 2000).

Muitas empresas, preferencialmente as grandes, utilizam diversas formas de inovação que contribuem para os processos produtivos, entre outros processos que apresentam precisão tecnológica, um exemplo é os centros de pesquisa e desenvolvimento $(\mathrm{P} \& \mathrm{D})$ de tecnologias próprias para serem introduzidas internamente. Entretanto, as pesquisas de desenvolvimento tecnológico se concentram apenas na empresa sede, nas filiais a atenção é para produtos (TIGRE, 2006).

De acordo com Schumpeter (1961) a partir da conquista de mercados diferentes e o aumento de empresas concorrentes, as empresas nunca permanecem sem alterar o processo ou mudar sua forma de trabalhar, possuem sempre novos modos de produção para permanecer, crescer e conquistar clientes, a partir disso, estará sempre compondo os quadros de oferta e demanda resultado da necessidade de inovar.

Para Tigre (2006), tecnologias recentes disponíveis no mercado que ainda não possuem demanda suficiente para expandir informações podem ocasionar gargalos se introduzidas em algum processo, à dependência de acesso à fábrica de origem acaba por 


\section{SILVA; SILVA}

prevalecer, enquanto necessidade corriqueira de solução de problemas permanece debilitada para as paradas com a tecnologia nova em busca de informações mais precisas.

\subsubsection{Inovação de produto}

A inovação de produto é o lançamento de um serviço ou bem novo ou melhorado no que interessa suas qualidades, são exemplos: restaurações relevantes em especificações técnicas, componentes e materiais, softwares incorporados, simplicidade de uso ou outras qualidades funcionais. Para isso acontecer é preciso novas tecnologias e conhecimento. Um aperfeiçoamento de um recente uso para um produto com poucas alterações para suas informações técnicas é uma inovação de produto (MANUAL DE OSLO, 2005).

Um dos desafios para as empresas que desejam ter um desempenho nas vendas e na suas mercadorias é a inovação de produto, pois acontece uma mensuração que foge de um modelo único, proporcionando uma análise nos processos e nas estruturas para o surgimento de novos produtos (MANTHEY et al., 2016).

Segundo Terra, et al. (2015) uma inovação de produto pode ser um bem ou serviço novo ou um produto existente aperfeiçoado. Quando ocorre essa mudança, muitas vezes os processos também mudam para acompanhar esse produto com diminuição de custo em relação à produção e diferenciação da concorrência, isso resulta no crescimento de lucratividade da organização.

Muitas empresas não dão tanta importância quando o assunto é produto pelo fato de ser algo simples, só que realmente não é simplesmente assim é importante que tenha o projeto do produto que conta com ajuda de analista de marketing, diretores de arte, previsores de vendas, engenheiros, especialista em finanças para pensarem e planejarem de maneira estratégica que envolve materiais, medidas, desenhos etc. (REID et al., 2005).

Para implantar uma inovação de produto terá custo referente a vários aspectos para a produção desse novo produto, aspectos como: mão de obra, matéria prima, financeiro aplicado nesse investimento entre outros. Vale ressaltar que esse dinheiro aplicado dará resultados futuros que as organizações precisam, mas o tempo para que esses resultados cheguem varia de empresa para empresa, devido à necessidade e a inovação que foi aplicada de cada uma (MANTHEY et al., 2016). 


\section{SILVA; SILVA}

O cuidado ao inovar deve ser um assunto bem importante para empresas, pois inovar não quer dizer que só terá vantagens, tudo depende do ponto de vista das organizações e também a forma de trabalhar e fabricação desse novo produto. Um exemplo claro sobre esse assunto seria um novo produto com baixa qualidade que irá trazer só resultados contrários sem benefício algum, por isso a certeza da necessidade de conhecimento, compartilhamento de tecnologia e participação de projetos entre outros (SEVERO et al., 2014).

Para chegar a uma inovação de produto ou qualquer inovação é necessário que a empresa tenha muita informação, e adquirir conhecimento para poder então colocar em prática, dessa forma diminui as chances de errar e aumentar a lucratividade, empregos, vendas e produtividade (TERRA et al., 2015).

Os clientes estão cada vez mais exigentes e atender a esses pedidos se torna uma tarefa difícil, mas são objetivos e metas das organizações fazer com que conseguiam superar essas dificuldades com a utilização de práticas e ferramentas estratégicas. A inovação de produto nesse caso torna-se uma ferramenta para satisfazer seus clientes possibilitando a vantagem competitiva (MANTHEY et al., 2016).

De acordo com Severo et al. (2014) são vários processos e pessoas que vão fazer parte para que essa inovação aconteça, com o objetivo de trazer resposta dos clientes sendo reclamações e sugestão, então todos tem que ter acesso a essa tecnologia e aprender lidar com ela, otimizando em todos os aspectos e entender que um liga ao outro.

Para Reid et al. (2005) produtos tangíveis são palpáveis, ou seja, bens, objetos entre outros, já os produtos intangíveis são os serviços (não palpável). Todo produto possui um ciclo de vida que são divididos em: introdução, crescimento, maturidade e declínio. A introdução é o lançamento do produto com vendas e lucratividade baixa. $\mathrm{O}$ crescimento se dá através da procura por aquele produto provocando o aumento de vendas e surgimentos de concorrentes. Depois dessa fase as vendas dos produtos estabilizam chegando à maturidade. No declínio o produto fica obsoleto e será trocado por outro futuramente.

Foi denominado em (4 Ps) da inovação, que nos quais consiste, inovação de produto, quando ocorrem mudanças nos produtos e serviços. Inovação de processo, quando ocorre a mudança na maneira de produzir ou nas máquinas utilizadas para 
produzir. Inovação de posição, quando ocorre mudança no ramo dos produtos. Inovação de modelo, quando ocorre mudança na forma que orientam as empresas (TIDD et al., 2008).

\subsubsection{Inovação organizacional}

Inovação organizacional é a realização de um novo estudo das técnicas de negócios da organização, no ambiente de trabalho e no meio externo, por meio da diminuição de custos, provoca-se uma melhoria no funcionamento da empresa e no ambiente de trabalho. Quando ela se relaciona em práticas de negócio, alcança novas técnicas para a empresa do cotidiano e recursos para direção do serviço. Permite-se a realização de novas práticas para beneficiar a distribuição do conhecimento dentro da organização (MANUAL DE OSLO, 2005).

A inovação organizacional é distinta dentro de uma organização, a primeira consegue ser modificada e aplicada por outra empresa, à segunda é que faz a organização ter exclusividade no mercado conseguindo a admiração e bom desempenho, pois trabalha de acordo com sua cultura que é própria, contudo, o ambiente organizacional deve ser propício para os funcionários terem a capacidade de fazer da tecnologia uma fonte de surpresas no mercado (TIGRE, 2006).

De acordo com Tidd et al, (2008) as pequenas empresas tomam decisões mais rápida que as maiores, mas a inovação pode estar presente em qualquer uma, independentemente do tamanho, e com esses argumentos percebe-se que as pequenas empresas devem inovar em busca constante de melhorias. Para se destacar é preciso não ser igual às outras, pois várias funções procedem diferentemente.

O tamanho da organização influencia para uma maior capacitação e elevada concentração tecnológica dentro de sua planta, nenhuma empresa possui intenção de expandir seu prédio se não tiver uma boa tecnologia para acompanhar o crescimento, logo, sucede em processos diversificados que ocupam espaço amplo o suficiente para atender a escala produtiva (TIGRE, 2006).

As mudanças surgem devido às tecnologias que estão sempre inovando e trazendo melhorias para a empresa. Não é a tecnologia que faz a diferença a ponto de solucionar os problemas, mas os resultados que surgirão, faz valer a pena o investimento. Propostas que visam à inovação contam com a ajuda dos colaboradores, no mundo de competividade atual (KUSTHER et al., 2010). 
Segundo Oliveira et al. (2008) para ocorrer uma melhoria necessita-se de mudança, não só para a empresa, mas para os funcionários que vão ter que se adequar a essa alteração, acaba sendo uma maneira de sobrevivência para as organizações, mudando o comportamento humano, a estrutura, estratégias, cultura e tecnologia entre outras coisa, para poder chegar nos resultados que almeja, alcançando a meta e ganhando vantagem competitiva. Passar por esses momentos de alteração não é uma tarefa fácil, requer muitos recursos e investimentos e corre o risco de não dar certo.

A inovação organizacional adentra-se nas alterações que envolvem as pessoas, incluem-se aqui os diversos departamentos existentes e que fazem as atividades empresariais funcionarem, compreende assim, o comportamento dos profissionais que direcionam o contato com clientes internos e externos da organização, além de como se dá a capacitação desses funcionários a ponto de ocorrer mudanças inovadoras no modo de trabalho (TIGRE, 2006).

Incluir tecnologia é possuir vantagem competitiva porque muitas empresas entram em falência por não conseguir se atualizar ou se adequar às mudanças de empresas do mesmo ramo. Outra dificuldade a ser driblada é lidar com as pessoas, pois eles estão acostumados ao existencial, distribuído dentro da empresa, portanto, fazer acontecer mudanças exigirá esforços para o treinamento (KUSTHER et al., 2010).

\subsubsection{Inovações quanto à intensidade}

Para Santini e De Souza (2006) a inovação é dividida nesses aspectos distintos:

Radical: é definido com um produto tecnologicamente novo cujas qualidades tecnológicas ou usos almejados diferenciam expressivamente dos produtos antecipadamente produzidos. Essas inovações podem apropriar tecnologias completamente novas, podem ser fundamentados nas combinações de tecnologias existentes, ou derivados do uso de novas ideias.

Incremental: é definido como um produto tecnologicamente melhorado, cujo desempenho foi expressivamente aprimorado ou inovado. Um simples produto pode ser melhorado em aspecto como de menor custo por meio do uso de elementos ou materiais de um bom desempenho.

Para Dos Santos et al. (2011) as inovações podem ser classificadas como: inovação incremental, inovação radical, novo paradigma técnico-econômico: 


\section{SILVA; SILVA}

- A inovação incremental pode acontecer com maior ou menor intensidade, mas com constância, nas indústrias e atividades de serviço; essa ocorre devido as invenções e melhorias que engenheiros e profissionais capacitados sugerem, cujos trabalhos são voltados para o processo de produção e das sugestões e iniciativas de usuários; elas podem surgir, também, embora com menos frequência, de programas organizados de pesquisa e desenvolvimento; é possível que os colaborados produzam soluções criativas para melhor atender a clientela, que nas etapas produtivas nasçam alternativas inovadoras ou modificadoras de produtos de um insumo, que caracterizam a inovação incremental.

- A inovação radical rompe o caráter contínuo da inovação incremental e é possível, apenas, em ambientes que se preocupam com o aperfeiçoamento, dos objetos examinados; vários setores da economia são afetados com as mudanças do sistema tecnológico, que são causa direta de entrada de empresas em novos setores, expandindo suas possibilidades de atuação no mercado.

- As inovações tecno-econômicas, também conhecidas como paradigma tecno-econômico, afetam as estruturas de produção e distribuição em diversos ramos da economia, quase que em sua totalidade. São um processo de seleção econômica do âmbito de inovações técnicas de grande impacto na vida prática e da sociedade, e consequentemente na economia, o que não é tão frequente, mas que envolve um processo, geralmente, longo de desenvolvimento (DOS SANTOS, et al., 2011).

\section{Procedimentos metodológicos}

A abordagem qualitativa é utilizada em pesquisa em que a preocupação maior é a interpretação de fenômenos e a atribuição de resultados e que direcionam a pesquisa a segmentos específicos, buscando embasar informações numa análise comparativa com a literatura da área de pesquisa (YIN, 2015; GODOI et al, 2010; DIAS; SILVA, 2010).

O estudo de caso é uma investigação empírica em que se faz um estudo intenso e exaustivo. Por envolver poucos elementos, permite amplo e detalhado conhecimento sobre o caso. É uma metodologia de pesquisa poderosa que combina entrevistas em grupos e individuais; com analise de registros e observação. Seu objetivo é de obter panoramas múltiplos de uma única organização (YIN, 2015; COOPER; SCHINDLER, 2011). 
Tendo em vista que esta pesquisa foi sobre o caso exclusivo de uma organização pública, com estudo particular sobre uma atividade específica (a adoção de inovação), descrevendo os procedimentos e características desse caso. Esta é uma pesquisa qualitativa-descritiva, com abordagem de Estudo de Caso e apoio no suporte teórico, característica da pesquisa bibliográfica (YIN, 2015; ROESCH, 2012; COOPER; SCHINDLER, 2011; FONSECA, 2002).

A coleta dos dados seguiu a um roteiro previamente estruturado, organizado a partir da literatura que formou o suporte teórico. O roteiro foi utilizado para direcionar a entrevista com vistas a atingir o objetivo da pesquisa. A entrevista teve um registro das informações prestadas pelo entrevistado (chefe do instituto de identificação e Papiloscopista da Unidade Regional de Perícias de Paranaíba/MS). A entrevista ocorreu presencialmente e, após, foi transcrita. Ainda, utilizou-se de observação não participante, as quais foram registradas em diário de campo.

A análise do material colhido seguiu aos procedimentos comuns da análise de conteúdo, confrontando o material colhido na entrevista e na observação com o suporte teórico pesquisado (COOPER; SCHINDLER, 2011; BARDIN, 1979).

\section{Apresentação e análise dos resultados}

A Coordenadoria Geral de Perícias é um órgão da Secretária de Estado de Justiça e Segurança Pública (SEJUSP) responsável pela realização das perícias oficiais e identificação do Estado de Mato Grosso do Sul. A Unidade Regional de Perícias e Identificação (URPI) de Paranaíba tem o objetivo de prestar serviços ao estado, às delegacias e aos cidadãos. É constituído por três setores: Instituto de Identificação, Instituto de Medicina Legal e Instituto Criminalístico. O setor pesquisado foi o Instituto de Identificação, que possui três servidores públicos ocupando o cargo de Papiloscopista. Até o ano de 2008, o processo de produção de identidades era realizado na primeira Delegacia de Polícia. Hoje, o Instituto de Identificação é instalado na URPI.

\subsection{Apresentação dos dados}

O entrevistado foi um servidor público estadual que desenvolve atividades como perito papiloscopista há 15 anos. Precipuamente, realiza a confecção de 


\section{SILVA; SILVA}

documentos, pericias e outras atividades inerentes ao cargo de chefe do posto de identificação.

Até o ano de 2014, a prioridade no atendimento era organizada pela ordem de chegada, o servidor distribuía senhas e atendia até o fim do expediente. Às vezes algumas pessoas, mesmo com senhas em mãos, ficavam sem atendimento; o ambiente físico não suportava grande número delas, não promovia conforto para quem esperava, algumas aguardavam em pé ou mesmo do lado externo do prédio.

Com o objetivo de atender melhor a população, reduzir o tempo de espera dos usuários, e agilizar o processo de atendimento foi implantada uma inovação no processo: o agendamento on-line - iniciou, primeiramente, na capital do Estado e em seguida ampliado para as demais sedes de unidades regionais.

Para ter acesso ao atendimento eletrônico, o usuário deve conectar-se ao site da Secretaria de Segurança Pública de Mato Grosso do Sul, selecionar a cidade em que deseja ser atendido, após o posto de identificação, o local e data desejada, preencher corretamente o formulário e confirmar o agendamento. Em seguida o requerente receberá em seu e-mail o protocolo de agendamento no qual constarão os dados do requerente: o dia, hora e local que será atendido, a relação dos documentos com apresentação obrigatória para confecção da carteira de identidade, sendo ela primeira ou segunda via e demais informações pertinentes a confecção do documento.

O processo de produção de identidades possui algumas etapas:

$1^{\circ}$. Agendamento eletrônico: através do site: 〈serviços.sejusp.ms.gov.br>.

$2^{\circ}$. Comparecer no dia, hora e local marcado para o atendimento, neste é realizado o processo de conferência da documentação exigida, cadastro do requerente junto ao Sistema de Gestão Integradas (SGI), coletas de digitais, assinatura e fotos. Lembrando que nesta etapa as cópias e documentos são recolhidos.

$3^{\circ}$. Nesta fase, há uma análise no tocante as impressões digitais, em que são analisadas para evitar duplicidade na documentação ou até mesmo geração de documentos falsos, simultaneamente ocorre o envio dos documentos recolhidos para o Instituto de Identificação de campo grande, onde encontra-se o arquivo de todo o Estado, local onde é realizado conferência dos mesmos e posteriormente arquivados;

$4^{\circ}$. Nesta última etapa ocorre a geração da carteira de identidade, a qual tem um prazo de cerca 5 dias úteis para chegar em seu local de origem, isto devido ao prazo do 


\section{SILVA; SILVA}

envio do malote, local onde fica aguardando pela sua retirada em um prazo máximo de 730 dias.

Este processo de inovação não é rígido, mas flexível. Por exemplo, as pessoas idosas ou mais carentes geralmente possuem dificuldades em acessar a internet. Os papiloscopistas sabendo disso abrem exceções, atendendo essas pessoas que não realizaram o agendamento on-line.

O processo de produção das carteiras de identidades vem sofrendo constantes aprimoramentos. Teve início com a mudança do local utilizado para confeccionar os documentos, migrando da delegacia de polícia para atender em prédio próprio, o que proporcionou um ambiente mais agradável, principalmente para os mais idosos que geralmente ficavam constrangidos em entrar na delegacia.

Em 2011, o sistema de produção das carteiras de identidade, que eram produzidas com a utilização de tinta, assinatura do requerente direto na cédula, classificação das digitais manualmente, que também conhecido como processo off-line. Com a mudança tudo passou a ser on-line, em que fotos digitais, assinaturas, são todos coletados através de câmera acoplada ao sistema de identificação. É importante salientar que com esta mudança o processo de atendimento se tornou muito mais ágil. Antes um documento demorava algo em torno de 60 a 90 dias para ser entregue com o advento da tecnologia este prazo passou para aproximadamente 5 a 15 dias.

Logo, em 2014 ocorreu a implementação do sistema on-line de agendamento, uma inovação que trouxe conforto e agilidade no processo tanto para a população quanto para os funcionários, e resultou em uma nova aparência no seu produto final que é a identidade.

Em 2016, houve novas mudanças no sistema, porém utilizando do agendamento eletrônico, onde foram instalados novos sistemas contra fraude, cruzamento de dados on-line, e geração de carteira instantânea com gráfica na capital do estado, investimentos estes que permite ao requerente ter acesso ao seu documento no prazo de 5 dias úteis, isto devido ao prazo do malote.

Juntamente com as mudanças nos sistemas, o Instituto de Identificação recebeu novos equipamentos como: computadores e câmeras novas, com uma tecnologia avançada. Para realizar as mudanças nos sistemas e receber novos equipamentos foi necessário reformar o espaço físico do ambiente de atendimento. Até o ano de 2016, a 


\section{SILVA; SILVA}

sala de atendimento era apertada, tinha capacidade de atender somente uma pessoa por vez, possuía três computadores, um com o sistema de emissão de identidade e os outros dois para produção de documentos. Com a inovação organizacional, quebraram uma parede da sala ao lado e criaram uma sala grande, para suportar os novos equipamentos, que contam com dois computadores para emissão exclusiva das carteiras de identificação e capacidade para atender duas pessoas ao mesmo tempo. Ao lado, mais dois computadores para realizar outras atividades.

Os papiloscopistas prestam serviços uma vez por semana na delegacia de Cassilândia, que por não possuir infraestrutura e equipamentos para implantação de tais inovações apresentadas, até os dias de hoje atendem com o sistema off-line. Portanto, não podem oferecer as mesmas condições que na unidade de Paranaíba, dificultando o processo produtivo.

\subsection{Análise dos dados}

Com o intuito de melhorar o atendimento e agilizar os serviços prestados à população, o instituto de identificação progrediu na produção de carteira de identificação, implantando alguns tipos de inovações: de processo, de produto e organizacional.

A inovação de processo trouxe melhorias na produção com novas técnicas de agendamento on-line, e consequentemente obteve qualidade na produção, promovendo mais agilidade e eficiência (MANUAL DE OSLO, 2005).

Inovar um processo inclui mudanças que modificam total ou parcialmente as atividades para formar determinado produto. Quando a tecnologia é introduzida, tornase grande aliada no aperfeiçoamento dos produtos. Com a aquisição de novos equipamentos tecnológicos, o Instituto de identificação sofreu mudanças essênciais e obeteve resultados positivos (TIGRE, 2006).

O produto novo pode ser semelhante a um produto existente, mas possui características que se diferencia, isso ocorre devido às tecnologias que dão uma nova utilidade para esse produto ou até mesmo a aparência, fazendo com que ele se torne moderno. A carteira de identidade atual obteve mudanças que modificaram sua aparência, com todos os registros digitais (ROCHA et al., 2016). 
Para o Manual de Oslo (2005), as questões de inovação devem compreender períodos específicos, que não abrange pesquisas que ultrapassem três anos, nem sejam inferiores a um. O processo de produção de carteira de identidade, vigente na delegacia da cidade Cassilândia, em que os papiloscopistas atendem uma vez por semana, futuramente poderá ser modificado de off-line para on-line. Contudo, somente após um ano entraria na classificação de inovação.

Para o Manual de Oslo (2005), existem fatores relacionados aos objetivos e efeitos (impactos) das inovações, será destacado somente as ocorridas na empresa pesquisada:

Competição demanda e mercados: com a implementação da inovação de processo houve uma mudança, na redução de tempo de atendimento e entrega dos documentos, para melhor atender as necessidades da população;

Produção e distribuição: a carteira de identidade digital, foi um resultado na qualidade dos bens e serviços, com as novas tecnologias obteve-se o aumento da capacidade de produção, redução dos tempos de produção, aumento da velocidade do fornecimento e distribuição de bens e serviços;

Organização do local de trabalho: As melhorias das condições de trabalho foram uma inovação de processo e organizacional, pois a empresa transformou o local de trabalho, realizou uma reforma e aumentou o espaço físico, para um melhor conforto tanto para os funcionários tanto para a população; juntamente a unidade recebeu novos equipamentos tecnológicos para um melhor processo de produção.

\section{Considerações Finais}

O objetivo da pesquisa foi identificar as inovações e suas contribuições utilizadas na produção de carteira de identidade. Estes objetivos foram atingidos, conforme pode ser observado na apresentação do estudo de caso (e análise). Identificouse a existência de três tipos de inovação: por processo, por produtos e organizacionais. Outrossim, foi possível apresentar as contribuições em que essas inovações trouxeram para a organização pesquisada.

Dentre as melhorias que a inovação tecnológica trouxe, destacam-se: as condições para recepcionar os requerentes; diminuição da fila de espera; minimização no tempo da entrega dos documentos; maior segurança para o requerente e para o estado; otimização nas condições de trabalho. Como resultado, ainda que a produção de 


\section{SILVA; SILVA}

carteira de identidade tenha aumentado, o requerente é atendido em menos tempo, porque já traz consigo a documentação correta.

Um contraponto encontrado, que é uma restrição ao processo produtivo, é a escassez de servidores na produção de carteira de identidade. Esta é uma das princípais barreiras que o órgão pesquisado enfrenta, pois nesse trabalho necessita-se de mão de obra efeitiva para realização e desenvolvimento da inovação.

Esta limitação foi apontada no Manual de Oslo (OECD, 2005), indicando que as empresas podem enfrentar barreiras para implantar a inovação decorrente da ausência ou carência de mão de obra. Ainda, a limitação pode ser quanto à qualificação dos funcionários, o que pode prejudicar suas atividades em virtude do desempenho crítico dos funcionários decorrentes da falta de conhecimento na utilização das novas tecnologias. Assim, a empresa tem restrições para encontrar profissionais qualificados para as novas atividades decorrentes da adoção da inovação.

Genuino e Machado (2013) identificaram que no caso da adoção da inovação radical, da qual decorrem mudanças bruscas no processo produtivo, há a necessidade de reestruturar a empresa, modificando significativamente os processos anteriormente utilizados. Uma vez que a organização pesquisa adotou uma inovação radical, consequentemente transformando o processo produtivo, se por um lado obteve ganhos, o fato de que o novo processo produtivo depende de que o sistema esteja on-line é outra limitação, posto que com a queda da internet, interrompe-se a produção das carteiras de identidade.

Decorrentes das duas limitações, duas propostas de intervenção se apontam:

$1^{\text {a }}$ Gestão de Pessoal: investimento nesse departamento, tanto na contratação (quantidade) de novos funcionários, como no treinamento (qualidade) dos funcionários; e,

$2^{a}$ Gestão de Tecnologia da Informação de Comunicação (TIC): investir no sistema, equipamentos e internet.

Como proposta para estudos futuros, propõe-se uma pesquisa quantitativa que vise a identificar a percepção dos clientes acerca da adoção da nova tecnologia. 


\section{Referências}

BARDIN, L. Análise de conteúdo. Lisboa: Edições 70, 1979.

COOPER, D. R., SCHINDLER, P. S. Métodos da pesquisa em administração. 10. ed, Porto Alegre: Bookman, 2011.

DIAS, D. S.; SILVA, M. F. Como escrever uma monografia: manual de elaboração com exemplos e exercícios. São Paulo: Atlas, 2010.

SANTOS, A. B. A; FAZION, C. B.; MEROE, G. P. S. inovação: um estudo sobre a evolução do conceito de Schumpeter. Caderno de Administração. Revista da Faculdade de Administração da FEA. ISSN 1414-7394, v. 5, n. 1, 2011.

FONSECA, J. J. S. Metodologia da pesquisa científica. Fortaleza: UEC, 2002.

GENUINO, S. L. V. P.; MACHADO, A. G. C. Pesquisa \& Desenvolvimento com inovação aberta: o caso EMEPA. XVI SemeAd, ISSN 2177-3866, 2013.

GONÇALVES, J. E. L. As empresas são grandes coleções de processos. Revista de administração de empresas. V. 40, n. 1, p. 6-9, 2000.

GODOI, C. K.; MELLO, R. B.; SILVA A. B. Pesquisa qualitativa em estudos organizacionais: paradigmas, estratégias e métodos. São Paulo: Saraiva, 2010.

KUSTHER, E. A.; BINOTTO, E.; SIQUEIRA, E.; NOGUEIRA M.; CASAROTTO E. Inovação tecnológica e suas influências no processo de gestão: uma análise no setor de segurança privada patrimonial. Revista Gestão Organizacional. v. 3, n. 1 - Jan./Jun. 2010.

LIMA, M. A. M.; MENDES, J. P. F. Inovação na gestão organizacional e tecnológica: conceitos, evolução histórica e implicações para as micro, pequenas e médias empresas. Revista Produção OnLine. ISSN 1676-1901. v. 3. n. 2. Junho de 2003.

MANTHEY, N. B.; VERDINELLI, M. A.; ROSSETTO, C. R.; CARVALHO, C. E. Desempenho da Inovação de Produto: Teste de uma Escala para Aplicação em PME's. Revista Ibero-Americana de Estratégia, v. 15, n. 4, p. 43-62, 2016.

OECD - Organização para a cooperação e desenvolvimento econômico. Manual de Oslo: diretrizes para a coleta e interpretação de dados sobre inovação tecnológica. 3. ed. Finep - tradução para o português, 2005.

OLIVEIRA S. A.; CANUTO K. C.; SEGATTO-MENDES A. P.; MANFIO F.; MUSSI F. B. Mudança organizacional e inovação tecnológica em processos: Estudo de caso em uma empresa prestadora de serviços do estado do Paraná. XXI Simpósio de gestão da inovação tecnológica ANPAD. Brasília, DF- 22 a 24 de out. 2008.

ROCHA, A. F. R.; VIEIRA, A. M. Aprendizagem Organizacional e Inovação de Produtos: estudo em Empresas de Base Tecnológica do Vale da Eletrônica (MG) . Caderno Profissional de Administração da UNIMEP, v. 6, n. 1, p. 108-131, 2016. 
REID, R. D.; SANDERS, N. R. Gestão de operações. Rio de Janeiro: LTC, 2005.

ROESCH, S. M. A. Projetos de estágio e de pesquisa em administração. São Paulo: Atlas, 2012.

RITZMAN, L. P.; KRAJEWSKI, L. J.; Administração da produção e operações. São Paulo: Prentice Hall, 2004.

SLACK, N.; CHAMBERS, S.; JOHNSTON, R. Administração da produção. Tradução Henrique Luiz Corrêa. 3. ed. São Paulo: Atlas, 2009.

SANTINI, G. A.; SOUZA FILHO, H. M.; BÁNKUTI, S. M. S. Inovações tecnológicas em cadeias agroindustriais: alguns casos do segmento de processamento de carnes, leite e café no Brasil. Gepros: Gestão da Produção, Operações e Sistemas, v. 1, n. 2, p. 9, 2006.

SCHUMPETER, J. A. (1912). A Teoria do desenvolvimento econômico. 3.ed. São Paulo: Nova Cultural, 1988.

SCHUMPETER, J. A. (1943) O processo de destruição criadora. Rio de Janeiro: Zahar, 1984.

SCHUMPETER, J. A. Capitalismo, socialismo e democracia. Rio de Janeiro: Fundo de Cultura, 1961.

SEVERO, E. A.; OLIVEIRA, M.; GUIMARÃES, J. C. F. Inovação de produto em uma empresa de micro-ônibus. Revista Pretexto, v. 15, n. 4, p. 46-63, 2014.

TERRA, N. M.; BARBOSA, J. G. P.; BOUZADA, M. A. C. A Influência da inovação em produtos e processos no Desempenho de Empresas Brasileiras. Revista de Administração e Inovação, v. 12, n. 3, p. 183-208, 2015.

TIDD, J.; BESSANT, J.; PAVITT, K. Gestão da inovação. 3. ed. Porto Alegre: Bookman, 2008.

TIGRE, P. B. Gestão da inovação: a economia da tecnologia no Brasil. Rio de Janeiro: Elsevier, 2006.

YIN, R. K. Estudo de caso: Planejamento e Métodos. 5. ed. Porto Alegre: Bookman, 2015. 